\title{
Adenocarcinoma of the gallbladder and extrahepatic biliary tract
}

INSERM

\section{Source}

INSERM. (1999). Orphanet: an online rare disease and orphan drug data base. Adenocarcinoma of the gallbladder and extrahepatic biliary tract. ORPHA:424991

Adenocarcinoma of the gallbladder and extrahepatic biliary tract is a rare epithelial carcinoma, arising either in the gallbladder itself or from the epithelium lining the extrahepatic biliary tree, cystic duct and/or peribiliary gland, characterized by nonspecific symptoms, such as abdominal pain, jaundice and vomiting and sometimes mimicking benign biliary diseases. Chronic biliary epithelial inflammation (e.g. primary sclerosing cholangitis, cholelithiasis, choledocholithiasis, liver fluke infestation) is a major risk factor. 